\title{
Facebook versus Twitter: Which one is more credible in a South African context?
}

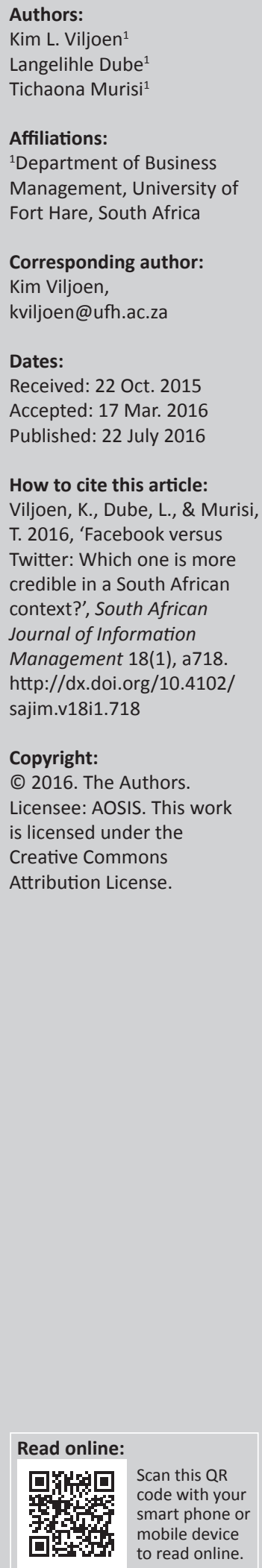

Background: Studies conducted have shown that half of the South African population uses either or both Facebook and Twitter social networking sites for social satisfaction and for the evaluation of products and purchase decisions. This is a direct result of the continuous technological advancements worldwide and the permeative nature of social media.

Objective: The focus of this study is to evaluate the credibility of Facebook and Twitter messages while establishing which of the mediums is perceived as more believable by consumers. The results of this research direct information technology practitioners, business managers, business owners, and marketing managers on the viability of these communication mediums.

Method: A positivistic paradigm was used in this study through the use of a descriptive research design which consisted of a survey of 446 respondents located in East London, Eastern Cape Province of South Africa. Respondents were either selected randomly or through convenience sampling and were between age 18 and 55 .

Results: It was established that both Facebook and Twitter are significantly related to the independent variable of 'intention to purchase', with Twitter having a stronger correlation with the independent variable than Facebook. The context of the study was set in relation to the purchase intention of specific mobile phone brands.

Conclusion: Based on these results, it can be concluded that Twitter electronic word-of-mouth can be considered to be more credible than Facebook electronic word-of-mouth; thus this should be considered when advertising or promoting products via these mediums.

\section{Introduction}

Consumers rely on opinions of others when making purchase decisions. The access to such opinions has been enhanced by the usage of the internet which serves as a prime platform for sharing content and information (Darban \& Li 2012). Narrowing down of the world into a global village has been facilitated by technological developments such as internet adoption in businesses. Internet usage has significantly matured on a global scale and businesses are currently harnessing the internet as a marketing tool in order to remain operational and competitive. Marketing activities of organisations have been made easier by internet adoption, and internet acceptance by consumers has allowed companies to reach an extensive audience when communicating. Intensified communication between firms and consumers has been aided by the development of social media networks which emerged with the internet era. Owing to attributes of accessibility, low cost, and effectiveness, social networking sites have become a central point for consumer conversations about products and services.

Increased inclusion of people on social networking sites has brought significant changes in consumer behaviour, empowering consumers with even more information for making purchase decisions (Johnson 2012). The information phase in the purchase decision making process has been widened and consumers are at liberty to evaluate various brands online before making the final buying decision (Lamb, Hair \& McDaniel 2013). Word-of-mouth (WOM) is a non-commercial form of communication among consumers widely recognised by marketers. Technological advancements resulted in the transition from traditional Wom to the electronic Wom known as the e-WOM (McBride 2011).

Social media relates to a number of websites that enable consumer interactions online. A number of social media sites have gained prominence in the past decade such as Facebook, Twitter, Friendster, and YouTube to mention just a few. With the upsurge in acceptance of social networks, the lives of communities have been changed and rapidly immersed in the communications on 
these sites. Conversations relating to consumer buying decisions form a significant part of discussions on social networking, with Facebook and Twitter having wide usage and familiarity (Chu \& Kim 2011). A study that was conducted with 500 people showed that $68 \%$ of the population today uses Twitter more than any other type of social media, revealing the power it possesses as an informational tool (Wilson 2013).

With reasons such as ease of use, familiarity, and low cost, Facebook has attracted commercial usage by businesses as a platform to reach a wider audience of consumers (Johnson 2012). Vast amounts of capital are injected by businesses to integrate technology with their business processes. Numerous businesses have established their names on virtual communities with accounts on Facebook, Twitter, and blogging sites being increasingly dominant (Darban \& Li 2012).

In marketing, credibility of communication is important for the successful establishment of brands amongst consumers Credibility in marketing terms refers to the trustworthiness of the information about products disseminated by businesses (Darban \& Li 2012). The internet today is full of huge quantities of information some of which is from untrusted sources and may contain errors which might be misleading. Past literature indicates that message credibility attracts brand preference and customer loyalty (Hoye \& Lievens 2009).

Brands have a considerable bearing on consumer behaviour and are often at the core of the daily purchase decisions of consumers (Wiid 2014). Tremendous changes in business approaches over the past years have witnessed increased inclusion of consumer opinions in the creation of company brands. Social media usage has accelerated this transformation with businesses extracting useful information for designing products from social networks. Brand names and images used to be developed and controlled by marketers; the shift has however allowed customers to participate in defining brands for businesses (Swanepoel \& Bothma 2013). A number of businesses have their fan pages on Facebook for example Samsung, Nokia, Blackberry, and Apple which give the customers room to contribute to brand development. The fan pages created on the social networking sites enable the growth of virtual brand communities which facilitate the creation of relationships among interested parties.

\section{Research problem}

The online information overload and consumers' dependence on the internet and social media for answers provide questions surrounding the issue of credibility of social media communication. This study seeks to analyse the credibility of both Facebook and Twitter messages, which can also be referred to as 'posts', and the potential influence they respectively have on consumer's intention to purchase different brands of mobile phones in South Africa. To date, there have been no studies conducted in South Africa that have investigated this problem.

\section{Research objectives}

The primary objective of this research project was to investigate Facebook message credibility versus Twitter message credibility and the resultant influence these mediums have on the probability to purchase mobile phones.

\section{Secondary objectives}

- To ascertain the level of Facebook message credibility and Twitter message credibility and to contrast the two.

- To determine the influence of Facebook messages on consumers' probability of purchasing different brands of mobile phones.

- To determine the influence of Twitter messages on consumers' probability of purchasing different brands of mobile phones.

\section{Literature review}

\section{Word of mouth}

Wom is a significant concept in consumer behaviour studies because of its impact on a number of behavioural aspects of customers (Labsomboonsiri 2012). Defined as informal communication between consumers about company products and brands, Wom is highly relevant in marketing and communication industries because of the threats and benefits derived from it (Toufaily, Souiden \& Ladhari 2013). Wom is not limited to face-to-face conversations; it also takes the form of other means of communication such as voice calls, voice messaging, and text messaging, amongst several others. Due to the telephonic conversations and face-to-face interactions with consumers, trust levels between customers and businesses are growing and this applies pressure on the customer-business relationship Wom messages steer attitudes and expectations about specific products due to the nature of their delivery from believable sources, which are generally trusted peers.

Positive Wom about a business and its products widens the customer base whereas unfavourable Wom leads to customer losses. With the inclusion of the electronic age in the global business environment, Wom has advanced to electronic word of mouth (e-Wom) (Doh \& Hwang 2009). Informal messages spread among consumers remain an indispensable element of contemporary marketing activities and now the internet, and social media in particular, have enabled them to affect consumer behaviour on a much greater scale than before (Tseng \& Hsu 2010). As has been indicated, these messages can also be referred to as 'posts' on social media.

\section{Electronic word of mouth}

As has been stated, the existence of e-Wom surfaced through the development of online interactions of consumers. These sites have manipulated the traditional Wom that occurred as verbal and face-to-face interactions to communications via internet platforms (Cheung \& Thadani 2010). E-Wom messages can either be positive or negative concerning a product on discussion, largely pioneered by opinion leaders 
within virtual communities (Xiaofen \& Yiling 2009). Opinion leaders are individuals who pioneer conversations and have an influence on the decisions of other consumers.

Numerous studies have been conducted to date on the ability of e-Wom to influence consumers' decision making. For example, 'How Electronic Word of Mouth Influences Brand Equity for Automotive Products in Indonesia' (Murtiasih \& Siringoringo 2013); 'The Effectiveness of Electronic Wordof-Mouth Communication: A Literature Analysis' (Cheung \& Thadani 2010); 'The Impacts of Online Word-of-mouth on Consumer's Buying Intention on Apparel: An empirical study' (Xiaofen \& Yiling 2009) and finally, 'How Consumers Evaluate e-WOM Messages' (Doh \& Hwang 2009).

E-Wom taking place on social media specifically significantly changed the face of marketing by providing a platform to meet the demands for increased consumer conversations. These virtual platforms not only assist in target marketing and product development but further allow marketers to assess themselves through consumer perspectives and compare themselves with other brands and businesses. Marketers paying attention to such conversations have the privilege of evaluating customer experiences with the organisations and making improvements based on such comments.

The power that e-Wom possesses is attributable to its ability to convey messages to a larger audience in a shorter space of time (Doh \& Hwang 2009). As a result e-Wom has been proven to be more powerful than traditional media methods such as newspapers, magazines, and television. Consumers are believed to value information shared by other consumers far more than the traditional communication blend of information disseminated by marketers (Murtiasih \& Siringoringo 2013). The existence of virtual communities enhanced the coalition of different people into a pool of trusted individuals through the sharing of personal information (Xiaofen \& Yiling 2009). These powerful communities have disempowered marketers' abilities to have a sole say in the product features, performance, and expectations. Thus, the need for understanding current consumer behaviour emanates from the notable shift of informational power from organisations to consumers.

More specifically, e-Wom has played a significant role in consumer purchase decisions through product and service reviews or comments made by others before engaging in a purchase. The evaluation of these reviews enables the consumer to have a comprehensive overview of the choices at hand that others have experienced. The presence of some antecedents to e-Wom like the direction and consensus of these messages also has an effect. Doh and Hwang (2009) state that positive reviews enhance the purchase of a particular product. However, Park and Lee (2009) indicate that the purchase decisions are more centred on reviewing the negative comments than the positive ones. Nonetheless, the review of online content is believed to have a significant impact on consumers' decisions when most of the messages are focused on a particular angle (Xiaofen \& Yiling 2009). The messages are anticipated to influence an action considered best by the consumer after the review. Furthermore, it is also believed that message characteristics tend to have a significant bearing on the effect of e-Wom on purchase decisions.

\section{Characteristics of e-Wom messages}

According to Yap, Soertarto and Sweeney (2013), there are two distinctive components in e-Wom messages, namely the cognitive and affective characteristics of each message. They define cognitive characteristics as 'the rational component of a message that typically refers to product attributes including performance, response to problems, and price-value perceptions'. These types of messages dealing with the product characteristics are usually disseminated by marketers as they are the ones possessing a remarkable understanding of the product on discussion ( $\mathrm{Xu}$ 2014). The affective component focuses on the emotional component of the message and such are deemed poor quality messages (Yap et al. 2013). This is so due to the interception of the true meaning of the message because of the senders' feelings attached to the review. These perceived low quality messages need to be combined with those possessing the cognitive component to produce a more credible output. The affective component of a message can be attributed to the sincerity of the source and friendliness. It can therefore be concluded that messages deemed to be clear and straight forward consist primarily of affective characteristics.

\section{Credible messages characteristics}

The structure of an online message on Twitter or Facebook has an effect on its credibility. Unorganised messages are viewed as less credible than well-organised ones. The unorganised message is likely to be perceived as such if it appears as if the sender lacks sufficient knowledge of the topic in order to be able to express it clearly Language of choice when conveying messages also affects its believability by other reviewers. Thus, a review posted in vernacular language leads to the perception of messages being less credible as it is considered to lack professionalism (Attan et al. 2012).

Extreme caution is required when individuals post content online to avoid miscommunication and misinterpretation from others, resulting in the purpose of the message being lost. Other factors that affect the credibility of messages are said to include message content factors such as information quality, language intensity, and message discrepancy stipulates.

As has been stated, positive comments about a product generally add to the likelihood that the product will be purchased by prospective customers (Sweeney, Soutar \& Mazzarol 2012). However, a review that is well written and is of a high standard generally has a magnified content, regardless of it being a positive or negative review (Gupta \& Harris 2010). Furthermore, it should be considered that the delivery of positive or negative comments depends on the individuals' agenda regarding the product and/or the 
business. Finally, the more recently the information has been posted online; the higher the perception of its quality (Johnson 2012).

\section{Facebook message credibility}

Facebook usage has had a huge impact in our society since its release in the year 2004. Facebook exists as a virtual community that allows users to belong to various groups formed on the network to facilitate the satisfaction of social needs. These groups usually consist of individuals who share similar or common characteristics that bond them together. The characteristics aforementioned could be the types of schools attended, religion, spending their leisure time, career paths, and even their relationship statuses.

The prime objective of the Facebook network was to bring together users to share their life experiences in a socially appealing atmosphere despite their differences and distances in-between. Facebook users were initially made up of friends, families, schoolmates, and workmates. The social media platform allows users to create profiles which can be seen by the public or friends only, depending on the options of the settings selected by the user. These profiles created enable users to add their personal information, residential areas, age, and whether one likes socialising with males or females among other details. Facebook conversations or posts take the form of videos, wall posts, status updates, likes, chats, photos, pokes, groups, and events. These conversations portray the users' daily lives and allow others to view their contents thereof.

The number of Facebook users has soared over the years and thus so has its usage. A way of explaining the popularity of Facebook lies solely in the theory of Maslow's hierarchy of needs (Wiid 2014). The need for social belonging and affiliation, which is a third order need, is satisfied by intrinsic rewards achieved via social media interaction (Smit et al. 2013). With the mobile phone purchase example, consumers will evaluate the various brands used by people close to them and other friends on Facebook in order to reach the final decision of which brand to buy. What other peers are conversing about on Facebook has a massive contribution to purchase decisions made.

The creation of fan pages on Facebook which occurred in November 2006 has enabled many organisations to advertise on the sites so as to reach a larger audience. Users will comment or like a businesses' page or brand page and such users will receive frequent updates pertaining to innovations and specials about the particular products or brands they have 'liked' (Mansfield 2012). The fan pages increase the organisation's market coverage and assist in the development of consumer's perceptions about their products and/or brands.

\section{Twitter message credibility}

Twitter is a microblogging online site that allows users to share content with each other. Twitter serves as an informational platform allowing messages of 140 characters to be tweeted on the web via computers and mobile phones thus the messages 'tweeted' are generally very brief. Blogging is a term used for user generated content which was found by Jorn Barger on 17 December 1997 naming it a weblog and the short form blog was introduced by Peter Merholz in 1999 (Swanepoel \& Bothma 2013). The use of blogs allowed users to drop down comments on each other's posts, allowed for posting of pictures, news, and updates about their lives with others. Blogs surfaced in various shapes and sizes hence the rise of microblogging sites like Twitter.

Twitter rebranded itself to become an informational source in 2010. It allowed users to create profiles and put their pictures on the web just as other social networks like Facebook. The socialisation element of Twitter was originally minimal, however as the platform gained momentum the level of socialisation via the medium increased in the form of retweeting and following others.

Twitter does not limit its users to individuals, but allows for companies to create profiles using the business name and brand symbols as profile pictures. A vast number of companies have tapped into this platform especially nonprofit organisations who have achieved their social presence through registering on Twitter (Mansfield 2012). Twitter e-Wom has wide coverage because of its use as an informational source and consumers seeking product information often make use of this platform. The platform allows for the evaluation of what others are saying pertaining to assorted products. Swanepoel and Bothma, (2013) indicate that because Twitter information is uncontrolled by marketers, some consumers may post destructive contents about a business or a product which may go viral and destroy its image as a result. This image tarnishing will be enforced by the need for belonging needs as consumers believe each other more than they do marketers. If a business is also available on Twitter, it can rebuild the damaged reputation by clarifying the reasons for their behaviour to consumers.

With the rising growth of Twitter usage, it has emerged as a strong tool for both marketers and consumers. Marketers are joining Twitter with the intention of creating social ties with consumers and tracking closely what is discussed about their products and competitors so as to create room for improvement (Waters \& Jamal 2011). Consumers do not only share adverse content about businesses and products, but also share their joys and happiness with products on the site, thus, helping each other with decision making and in turn enabling marketers to understand them better.

\section{Hypotheses}

With this in mind, it is essential for marketers to determine which internet related messages have higher levels of credibility and the effect thereof. Thus, the first hypothesis related to the credibility of Facebook is stated as follows:

- H1: Facebook messages' credibility have a significant relationship on the probability to purchase different brands of mobile phones. 
Following on from the discussion of Twitter's online meteoric rise as a communication channel the second hypothesis for this study can be stated as follows:

- H2: Twitter message credibility has a significant impact on the probability to purchase different brands of mobile phones.

\section{Research methodology}

Paradigms provide the foundations of any research strategy, and the chosen research methodology reflects the assumptions of the underlying research paradigm (Collis \& Hussey 2009). The objective of the strategy used in this study aimed at establishing the relationships between Facebook and Twitter message credibility with consumer purchase intention. As this study sought generalisation of results, the positivistic approach was most appropriate and this allowed the use of quantitative research methods. The use of a positivistic philosophy facilitates the applicability of a descriptive research design.

Data used in the study combined both primary and secondary sources, with the primary sources providing empirical data and the secondary sources providing the basis for the literature review. The study was tailored in terms of the criteria of a quantitative approach and that included the use of the survey method for empirical data collection.

The target population for this research project was comprised of Facebook and Twitter users over the age of 18 years residing in the East London area of the Eastern Cape. This study used a combination of both probability and nonprobability sampling methods. The non-probability sampling incorporated convenience and judgmental sampling techniques. Convenience sampling deals with a population that is easily accessible, hence a large portion of the sample consisted of University of Fort Hare East London students. Judgmental sampling was also used for the other segment of the sample that was comprised of non-college individuals. A snowball sampling strategy which falls under non-probability sampling was used specifically to obtain information from other members of the target population who are non-college students. The sample size was approximately 446 .

For the purpose of this study, a questionnaire was used as the research instrument and the design of the questionnaire followed that of Likert scales. The scales adapted for this study were previously used in other studies by Lin, $\mathrm{Wu}$ and Chen (2013) and Choi and Scott (2012). The message credibility scale was adopted from Lin et al. (2013) and the purchase intention scales from Choi and Scott (2012). Reliability and validity of the constructs were thus previously established in the Lin et al. (2013) and Choi and Scott (2012) studies, and were deemed to be of a high level. The questionnaire was divided into two sections, with the first section containing questions related to biographical data of the targeted sample. The scale portion of the questionnaire consisted of 20 statements.

\section{Data analysis}

Analysis of quantitative data makes use of statistical methods due to the numerical nature of the data; statistical inference uses the data collected from the sample to draw conclusions in relation to the population where the sample was drawn. Both descriptive and inferential testing was conducted on this data. The descriptive statistics merely included a depiction of the demographics of the sample respondents whereas the inferential statistics included test of reliability, validity, and significance of association. The reliability tests were conducted using the Cronbach's alpha score to indicate the internal consistency within the scales. Scales are sometimes reliable but invalid therefore, several sets of exploratory and confirmatory factor analyses were conducted to determine uni-dimensionality and thus validity of the constructs. Factor analysis is primarily used as a data reduction strategy so that items that remain are well correlated and thus sound results can be assured (Hellmueller \& Trilling 2012). Principal components analysis which considers the total variance in the data was used and all the independent variables were tested. Correlation coefficients were then used to explain the degree of relationship that exists between variables with a two-tailed significance test to provide a corresponding $P$-value. Correlations were regarded as significant at the 0.01 level. The research results obtained subsequently follow in the sections hereafter.

\section{Biographic analysis of respondents}

Of the 446 respondents surveyed, the demographic results show that the distribution of participation was fairly even across genders with $53 \%$ female and $47 \%$ male. Of the total respondents, the 18-27 year age groups dominated and made up $77 \%$ of the total respondents. The results of this study are thus skewed towards this particular consumer age group. However, it should be noted that the majority of Facebook and Twitter users in South Africa are the young generation aged between 18 and 30 years, thus marketers are predominantly targeting this group via social media (World Wide Worx 2012).

\section{Reliability and validity analysis}

With respect to the reliability of the scales, the Facebook message credibility scale attained a 0.804 score; Twitter message credibility 0.851 ; Facebook purchase intention 0.816 ; and the Twitter purchase intention scale ranked highest with 0.859 . Individual item reliability was tested for each scale thus; Facebook message credibility, Twitter message credibility, and purchase intentions for both Twitter and Facebook were measured separately. No modifications to the scales were necessary in order to achieve these acceptable Cronbach's Alphas, which all exceed 0.700 - the threshold level for acceptance.

As has been indicated, factor loadings represent the correlations between items representing the different variables. Higher factor loading coefficients for each variable exhibit a closer relationship between items which comprise 
each variable. It is essential that items 'load' onto their corresponding factors in order to ensure that specific variables can be considered to be valid. Facebook and Twitter message credibility factors were presented together with their factor loadings ranging from 0.688 to 0.776 and 0.734 to 0.877 respectively. With respect to the credibility scales, the Twitter and Facebook scales loaded separately from one another thus signifying that they each had a different focus despite their similarity. Higher coefficients existed between items in the Twitter credibility scale in comparison to the items loadings of the Facebook credibility scale. This therefore displayed that the items in the Twitter credibility variable were more aligned to each other in comparison to the ones for Facebook. The factors loaded separately, thus, the five items for Facebook scale loaded separately from the Twitter scales. This illustrates that each factor was uni-dimensional and respondents viewed the variables as unrelated to each other.

\section{Correlations}

Positive correlations explain the existence of a relationship between variables, whereas negative correlations indicate that there is no relationship between the variables measured (Berndt \& Petzer 2011). Table 1 indicates that there is a significant and relatively strong positive relationship between purchase intentions and Facebook message credibility, with a correlation coefficient of $0.412^{* *}$.

Table 2 indicates that Twitter credibility had a significant and stronger relationship with purchase intentions with a correlation coefficient of $0.569^{* *}$. This explains the significant relationship existing between the credibility of Twitter messages and the intention to purchase the mobile phone brands triggered by the use of the site; respondents showed a

TABLE 1: Correlations for Facebook message credibility and intention to purchase.

\begin{tabular}{lll}
\hline Variables & $\begin{array}{l}\text { Facebook purchase } \\
\text { intention }\end{array}$ & $\begin{array}{l}\text { Facebook message } \\
\text { credibility }\end{array}$ \\
\hline Facebook purchase intention & & $0.412^{* *}$ \\
Correlation coefficient & 1 & 0.001 \\
Sig (2-tailed) & 0 & 408 \\
$N$ & 446 & \\
Facebook message credibility & & 1 \\
Correlation coefficient & $0.412^{* *}$ & 0 \\
Sig (2-tailed) & 0.001 & 413 \\
$N$ & 408 & \\
\hline
\end{tabular}

**, Correlation is significant at the 0.01 level (2-tailed).

TABLE 2: Correlations for Twitter message credibility and intention to purchase.

\begin{tabular}{lll}
\hline Variables & $\begin{array}{l}\text { Twitter purchase } \\
\text { intention }\end{array}$ & $\begin{array}{l}\text { Twitter message } \\
\text { credibility }\end{array}$ \\
\hline Twitter purchase intention & 1 & $0.569 * *$ \\
Correlation coefficient & 0 & 0.000 \\
Sig (2-tailed) & 403 & 398 \\
$N$ & & \\
Twitter message credibility & $0.569 * *$ & 1 \\
Correlation coefficient & 0.000 & 0 \\
Sig (2-tailed) & 398 & 423 \\
$N$ &
\end{tabular}

**, Correlation is significant at the 0.01 level (2-tailed). higher level of credibility for Twitter than Facebook messages indicated by a $0.569^{* *}$ for Twitter and $0.412^{* *}$ for Facebook.

\section{Hypotheses testing}

The objectives of this study were to ascertain the level of credibility between Facebook and Twitter messages and the effect thereof on the probability to purchase different brands of mobile phones. Both factors have a significant relationship with the dependent variable, intention to purchase. A $P$-value of 0.001 was found for the relationship between Facebook message credibility and intention to purchase. The relationship between Twitter message credibility and intention to purchase was characterised by a $P$-value of 0.000 . As indicated previously, correlations were regarded as significant at the 0.01 level. For both hypotheses, the alternate hypotheses were accepted and the null hypotheses rejected. Overall it can be concluded that due to Twitter message credibility having a higher level of correlation with intention to purchase than Facebook message credibility, Twitter can be considered to be more credible than Facebook, specifically within the context of this study.

\section{Management implications}

Previous research studies conducted across the world reveal just how important Facebook and Twitter are in contributing to the consumer decision making process. This study enforces the fact that Facebook and Twitter are able to influence consumers in terms of their intentions to purchase specific mobile phone brands. This study further reveals that Twitter has a stronger relationship to influence purchase decisions than Facebook does.

The literature review provided various reasons why some messages are perceived to be more credible than others. The reasons range from the quality of the content, to the negative or positive slant of the message, to the composition of the messages cognitive and conative components. There are numerous reasons that an e-Wom message can be more powerful in Twitter form than Facebook form. An important reason to consider is that of opinion leaders; consumers only follow or retweet messages of people who they generally want to emulate, thus this could be the critical point that provides Twitter with a stronger influence on purchase intentions than Facebook.

Traditional marketing methods cannot and should not be phased out but organisational leaders, business managers, and marketers cannot afford not to have an online presence, specifically a social media strategy. It cannot be said that costs are a barrier in this regard as it has been established that both platforms are inexpensive to use as communication mediums. Businesses and the relevant people within those businesses need to ensure that they have both a Facebook and Twitter presence with a slightly stronger focus on Twitter than Facebook. In doing this they need to ensure that the information posted by their businesses is relevant and up to date and constantly carefully considered before posted. Twitter and Facebook accounts cannot be handled carelessly 
as once e-Wom is posted, it cannot be retracted as it will forever be in cyberspace. Furthermore, to the previous recommendation, business managers and marketers need to consider ways of actually selling merchandise directly from their Facebook and Twitter accounts as this would no doubt lead to an increase in sales.

It is recommended that this study be emulated with a different product to that of mobile phone brands to determine if the results are generalisable. Furthermore, this study needs to be replicated with a more even spread of respondents across the various age groups in order for the results to be said to be truly generalisable. It is then also recommended that further studies be conducted to deduce what other factors play a role in determining the credibility levels between Facebook and Twitter, as well as other online social platforms such as Instagram. Other factors that could be studied across these platforms include a more detailed analysis of information quality, trustworthiness of poster, and choice of wording, for example.

\section{Conclusion}

Creation of platforms between consumers, businesses, and marketers is crucial so as to earn consumer trust and grow product brands. Increased interaction between the different parties causes the relationship to mature and therefore promotes trust. This study assessed the effectiveness of Facebook and Twitter communications credibility on the probability to purchase different mobile phones brands by consumers. The acceptance of both the Twitter and Facebook alternate hypotheses in this study validated the fact that both platforms are able to significantly influence purchase intentions. However, it was deduced that Twitter credibility had a stronger relationship with the intention to purchase than Facebook did, indicating that Twitter is potentially a better e-Wom medium than Facebook. Suggestions to managers and marketers to use more of Twitter and Facebook, specifically Twitter, to communicate with customers and consumers, were provided.

\section{Acknowledgements Competing interests}

The authors declare that they have no financial or personal relationships which may have inappropriately influenced them in writing this article.

\section{Authors' contributions}

K.V. supervised students' projects, designed the study and questionnaire, conducted data analysis, refined the article, and attended to revisions. L.D. collected data and wrote the introduction and literature, and T.M. collected data and wrote methodology and findings.

\section{References}

Attan, A., Raof, A.H., Hamzah, M., Abdullah, K.I. \& Omar, N.A., 2012, 'Developing a profile of workplace written communication', Social and Behavioral Sciences 70, 969-978.
Berndt, A. \& Petzer, D., 2011, Marketing reseach, Pearson Education, Cape Town.

Choi, J.H. \& Scott, J.E. 2012, 'Electronic Word of Mouth and Knowledge Sharing on Social', Journal of Theoretical and Applied Electronic Commerce Research 8(1) $69-82$.

Cheung, C.M. \& Thadani, D.R., 2010, 'The effectiveness of electronic word-of-mouth communication: A literature analysis', Proceedings of the 23rd Bled eConference eTrust: Implications for the Individual, Enterprises and Society, June 20-23, Slovenia, 329-340.

Chu, S.C. \& Kim, Y., 2011, 'Determinants of consumer engagement in electronic word of mouth (eWOM) in social networking sites', International Journal of Advertising 30(1) 47-50. http://dx.doi.org/10.2501/IJA-30-1-047-075

Collis, J. \& Hussey, R., 2009. Businesss research. Palgrave Macmillan, New York.

Darban, A., \& Li, W., 2012, 'The impact of online social networks on consumers' purchasing decision: The study of food retailers', Masters Thesis, Jonkoping University.

Doh, S.-J. \& Hwang, J.-S., 2009, 'How consumers evaluate eWOM (electronic wordof-mouth) messages', Rapid Communication 12(2), 193-197. http://dx.doi.org/ 10.1089/cpb.2008.0109

Gupta, P. \& Harris, J., 2010, 'How e-WOM recommendations influence product considerations and quality of a choice: A motivation to process information perspective', Journal of Business Research 63, 1041-1049. http://dx.doi.org/ 10.1016/j.jbusres.2009.01.015

Hellmueller, L. \& Trilling, D., 2012, 'The credibility of credibility measures: A metaanalysis in leading communication journals', WAPOR 65th Annual Conference, Hong Kong, June, 1951-2011

Hoye, G.V. \& Lievens, F., 2009, 'Tapping the grapevine: A closer look at word-of-mouth as a recruitment source', Journal of Applied Psychology 94(2), 341-352.

Johnson, J.E., 2012, 'Use of product reviews as influenced by family, peers and online social networking usage: A look into modern consumer socialization', Masters Thesis, University of Nebraska.

Lamb, C.W., Hair, J.F. \& McDaniel, C., 2013, MKTG6, South-Western Cengage Learning, Texas.

Labsomboonsiri, S., 2012, 'Motivations for eWOM exchanges in an online community: Self-development, problem solving, support and relaxation', Australian Journal of Communication 26(3), 17-18.

Lin, C., Wu, Y.-S., \& Chen, J.C.V., 2013, 'Electronic word-of-mouth: The moderating roles of product involvement and brand image', TIIM 2013 Proceedings (pp. 39-47). Phuket, Thailand: Technology Innovation and Industrial Management.

Mansfield, H., 2012, Social Media for social good: A how- to guide for nonprofits. New York: Mc Graw-Hill.

McBride, D. L., 2011, 'Risks and benefits of social media for children and adolescents', Journal of Pediatric Nursing 26(5), 498-499.

Murtiasih, S. \& Siringoringo, H., 2013, 'How word of mouth influence brand equity for automative products in Indonesia', Procedia- Social and Behavioural Sciences 81, 40-44. http://dx.doi.org/10.1016/j.sbspro.2013.06.384

Park, C. \& Lee, T.M., 2009, 'Information direction, website reputation and eWOM effect: A moderating role of product type', Journal of Business Research 62, 61-67. http://dx.doi.org/10.1016/j.jbusres.2007.11.017

Smit, P.J., Cronje, G.J., Brevis, T. \& Vrba, M.J., 2013, Management principles, 5th edn., Juta \& Company, Cape Town.

Swanepoel, J. \& Bothma, C., 2013, Fundamentals of e-marketing, 2nd edn., Juta \& Company, Cape Town.

Sweeney, J.C., Soutar, G.N. \& Mazzarol, T., 2012, 'Word of mouth: Measuring the power of individual messages', European Journal of Marketing 46(1/2), 237-257. http://dx.doi.org/10.1108/03090561211189310

Toufaily, E., Souiden, N. \& Ladhari, R., 2013, 'Consumer trust toward retail websites: Comparison between pure click and click-and-brick retailers', Journal of Retailing and Consumer Services 20(6), 538-548. http://dx.doi.org/10.1016/j.jretconser. 2013.05.001

Tseng, F.M. \& Hsu, F.Y., 2010, The influence of eWOM within the online community on consumers' purchasing intentions- The case of the Eee PC, Department of International Business, Yuan Ze University, Taiwan, pp. 1-12.

Waters, R.D. \& Jamal, J.Y., 2011, 'Tweet, tweet, tweet: A content analysis of nonprofit organizations' Twitter updates', Public Relations Review 37(3), 321-324.

Wiid, J., 2014, Strategic marketing, 1st ed., Juta \& Company, Cape Town.

Wilson, C., 2013, Facebook knocks Mxit from its perch', viewed 25 March 2014, from World Wide Worx: http://www.techcentral.co.za/facebook-knocks-mxit-from-itsperch/43551/

World Wide Worx., 2012, World Wide Worx', viewed 03 April 2014, from Social Media Breaks barriers in SA: http://www.worldwideworx.com/socialmedia2012/

Xiaofen, J. \& Yiling, Z., 2009, 'The impacts of online word-of-mouth on consumer's buying intention on apparel: An empirical study', Proceedings of the 2009 International Symposium on Web Information Systems and Applications, Nanchang, China, May 22-24, 2009, 024-028.

Xu, Q., 2014, 'Should I trust him? The effects of reviewer profile characteristics on eWOM credibility', Computers in Human Behaviour 33, 136-144.

Yap, K.B., Soertarto, B. \& Sweeney, J.C., 2013, 'The relationship between electronic word-of-mouth motivations and message characteristics: The sender's perspective', Australasian Marketing Journal 21, 66-74. 